\title{
Psychosocial Distress in Caregivers of Patients with a Metastatic Solid Tumor in Routine Care: A Survey in a Community Based Oncology Group Practice in Germany
}

\author{
Stefan Feiten ${ }^{1}$, Vera Friesenhahn ${ }^{1}$, Jochen Heymanns ${ }^{2}$, Kristina Kleboth ${ }^{1}$, Hubert Köppler ${ }^{2}$, Ulrike Mergenthaler ${ }^{1}$, \\ Jörg Thomalla ${ }^{2}$, Christoph van Roye ${ }^{2} \&$ Rudolf Weide ${ }^{2}$ \\ ${ }^{1}$ Institute for Health Care Research in Oncology, Koblenz, Germany \\ ${ }^{2}$ Hematology/Oncology Group Practice, Koblenz, Germany \\ Correspondence: Stefan Feiten, Institut für Versorgungsforschung in der Onkologie, Neversstraße 5, 56068 \\ Koblenz, Germany. Tel: 49-(0)261-921-5693-23. Fax: 49-(0)261-921-5693-40. E-mail: s.feiten@invo-koblenz.de
}

\author{
Received: June 19, 2013 Accepted: July 4, 2013 Online Published: July 17, 2013 \\ doi:10.5539/cco.v2n2p1 URL: http://dx.doi.org/10.5539/cco.v2n2p1
}

This article contains original unpublished work. Parts of it were presented at the Annual Meeting of the German Society of Hematology and Oncology (DGHO) 2011 and at the San Antonio Breast Cancer Symposium 2011

\begin{abstract}
Introduction: Psychosocial distress in caregivers of cancer patients is highly prevalent, particularly in advanced stages. Little data is available concerning extent and main issues of caregivers' distress from patients who receive their treatment in an oncology group practice.

Methods: Standardized cross-sectional survey was administered to caregivers and patients with a metastatic solid tumor who were treated in a community based oncology group practice. Patients provided information concerning their caregivers and level of distress. Caregivers assessed level and main issues of distress. The extent of distress was evaluated using the Distress Thermometer (DT), main issues of distress were evaluated by the Hospital Anxiety and Depression Scale (HADS-D).

Results: 200 patients (35\% male) with a median age of 68 (38 - 93) were interviewed. DT mean score was 4.7 , with $35 \%$ scoring above cut-off $(>5) .90 \%$ named one or more caregiver, 1.3 were named in mean $(0-4) .137$ caregivers ( $42 \%$ male) with a median age of $61.5(25-86)$ were interviewed. DT mean score was 5.4 , with $48 \%$ scoring above cut-off $(>5$ ). According to HADS-D 20\% were anxious (cut-off $\geq 11$ ) and $15 \%$ depressed (cut-off $\geq 9$ ) in a clinical sense. With regard to the distress level of caregivers and patients, gender was not found to be a confounding variable although female patients showed higher distress levels than male patients.
\end{abstract}

Conclusion: Caregivers are screened as highly distressed, sometimes even more than the patients themselves. A significant proportion seems to be anxious and depressed and therefore should be offered help.

Keywords: distress, caregivers, anxiety, depression, routine care

\section{Introducation}

The role of a cancer patients' caregiver is often assumed with little or no preparation and without considering whether one has enough knowledge, resources or skills to cope with the situation (Northouse, Williams, Given, $\&$ McCorkle, 2012). Especially spouses and adult children often have to face many different responsibilities and to provide logistical as well as emotional support (Northouse et al., 2012; Götze et al., 2012; Zwahlen, Hagenbuch, Carley, Recklitis, \& Buchi, 2008). A review concluded that caregivers of cancer patients experience during and after the treatment phase a lot of physical, social and emotional problems, an impact on their daily life and increased responsibilities (Stenberg, Ruland, \& Miaskowski, 2010). Recent trends toward longer survival, outpatient treatment and home care have increased the number of caregivers and may have amplified their burden (Braun, Mikulincer, Rydall, Walsh, \& Rodin, 2007; Vanderwerker, Laff, Kadan-Lottick, McColl, \& Prigerson, 2005). In sum there is strong consensus in the literature that the situation of caregivers is influenced by a variety of stressors, especially in advanced stages (Heußner et al., 2009), but nevertheless results concerning distress' extent are heterogeneous. Estimations range from $20 \%-30 \%$ up to $50 \%$ in the advanced situation 
(Price et al., 2010). Two reviews further underline the heterogeneity of results by the reported distress levels between $10 \%$ and $50 \%$ (Stenberg et al., 2010; Pitceathly \& Maguire, 2003). One has to face the fact that many studies are only comparable in part because of different treatment settings, stages of disease, caregivers' gender, evaluation methods and cut-off values. Variables are often confounded and it is difficult to come to a precise estimation of the amount of caregivers' distress.

It seems to be obvious that patients and caregivers are involved in each other's coping and support processes (Hagedoorn, Sanderman, Bolks, Tuinstra, \& Coyne, 2008) and that both suffer to some extent from psychosocial distress. One could think that patients are more distressed because they suffer from cancer and its therapy. Furthermore could the increased responsibility of care provision lead to positive effects on caregivers' mental health (Grov, Dahl, Moum, \& Fosså, 2005). But there are numerous hints that caregivers experience the same or even a higher level of distress than the patients themselves. A meta-analytic investigation came to the conclusion that caregivers and patients experience the same distress level (Hodges, Humphris, \& Macfarlane, 2005) and two reviews revealed that, especially in advanced stages, the caregivers' psychological burden exceeds that of the critically ill patient (Northouse et al., 2012; Williams \& McCorkle, 2011).

During the last 20 years almost 600 experienced oncologists have founded 400 community based oncology practices in Germany caring for 600.000 cancer patients per year (Berufsverband der Niedergelassenen Hämatologen und Onkologen in Deutschland - BNHO e.V., 2013). These practices enable the oncology teams to deliver high quality cancer care close to the place of living of their patients. Thus patients can stay at home and receive psychosocial support from their relatives and friends. No data is available so far concerning extent and main issues of distress in caregivers of patients with metastatic solid tumors, who are treated in a community based oncology group practice. We undertook this survey to learn about these things in routine care.

The following points should be analyzed particularly:

1. Extent of patients' distress

2. Extent of caregivers' distress

3. Association between patients' and caregivers' distress

4. Impact of gender and role (patient vs. caregiver) on distress

5. Main issues of caregivers' distress

\section{Methods}

Standardized cross-sectional survey of caregivers and patients with a metastatic solid tumor who were treated in a community based oncology group practice in Germany between 04/2010 - 03/2011. Participants were recruited by consecutive sampling during the palliative treatment phase.

In total 200 patients and 137 caregivers were interviewed. All data was collected in a database and analyzed statistically using SPSS 19. Frequencies, medians and means were computed; mean differences were tested for statistical significance by t-tests for independent samples and by one- and two-way analyses of variance (ANOVA). Pearson's correlation coefficients were computed to identify associations. A reliability analysis was conducted using Cronbach's $\alpha$.

Overall 213 patients were approached by the attending physician, of which $200(94 \%)$ were available for a personal interview. Participating patients were asked in an open-ended question to identify their caregivers, defined as persons who support them in any respect of life and illness. 179 patients $(90 \%)$ named one or more caregivers (257 in sum), who were thus potentially qualified for the caregiver-interviews. A total of 137 personal or alternatively telephone interviews were conducted, representing a response rate of $53 \%$. All respondents gave written informed consent concerning interview, data analysis and data publication.

\subsection{Patient-Interviews}

In patient-interviews the degree of psychosocial distress was measured using the German version of the Distress Thermometer (DT) and the Problem List (PL) (Mehnert, Müller, Lehmann, \& Koch, 2006). In addition, some data concerning medical and social background was collected, but above all, the supporting caregivers of patients were identified.

\subsection{Caregiver-Interviews}

Along with DT, PL and some questions concerning social background the German version of the Hospital Anxiety and Depression Scale (HADS-D) (Herrmann-Lingen, Buss, \& Snaith, 2005) was used in caregiver-interviews to assess anxiety and depression. 


\subsection{Distress Thermometer (DT) and Problem List (PL)}

The DT has been validated in numerous empirical studies (Mergenthaler et al., 2011; Mitchell, 2007) and is recommended as a screening tool by the Working Committee for Psychooncology ("Arbeitsgemeinschaft für Psychoonkologie der Deutschen Krebsgesellschaft - PSO"). It is one of the most frequently used instruments in routine care and can be easily administered to patients and caregivers.

For the DT we decided to use a cut-off of $>5$, in contrast to the recommendations of the PSO, because we had found this value to be more useful in routine care. About one third of patients with a metastatic solid tumor had been screened as "distressed" in an outpatient setting according to this cut-off in prior investigations (Mergenthaler et al., 2011; Weide et al., 2012). According to Zwahlen et al. (2008) a cut-off value of $\geq 5$ (which means $>4$ ) achieves maximum sensitivity while maintaining an adequate level of specificity. Therefore the recommended cut-off $\geq 5$ is designated as well.

\subsection{Hospital Anxiety and Depression Scale (HADS-D)}

The HADS-D has been confirmed in numerous empirical studies (Bjelland, Dahl, Haug, \& Neckelmann, 2002; Gough \& Hudson, 2009) and is recommended as a screening tool by the PSO as well.

HADS-D cut-offs were defined according to a recent validation study (Zwahlen et al., 2008) as follows: Individuals with scores $\geq 9$ on the depression subscale were classified as a "depression case", individuals with scores $\geq 11$ on the anxiety subscale were classified as an "anxiety case". We further computed a total HADS-D score and investigated the association between this total score and the distress level according to the DT. A total score can be regarded as a distress score in general and is considered applicable by the authors of the German HADS version (Herrmann-Lingen et al., 2005).

\section{Results}

\subsection{Results of the Patient-Interviews}

200 patients with a metastatic solid tumor were interviewed. Patient characteristics are depicted in table 1.

Table 1. Patient characteristics

\begin{tabular}{lll}
\hline Patient characteristics & $\mathrm{N}$ & $\%$ \\
\hline Gender & 69 & 34.5 \\
- men & 131 & 65.5 \\
- women & & \\
\hline Age at the time of the interview & 63 & 31.5 \\
- up to 60 years & 59 & 29.5 \\
- 61 - 70 years & 78 & 39.0 \\
- older than 70 years & 68 years & $38-93$ \\
- median / range & & \\
\hline Diagnoses & 84 & 42.0 \\
- breast cancer & 30 & 15.0 \\
- cancer of the digestive organs & 21 & 10.5 \\
- lung cancer & 21 & 10.5 \\
- prostate cancer & 14 & 7.0 \\
- cancer of the urinary tract & 13 & 6.5 \\
- cancer of female genitals & 17 & 8.5 \\
- others & & \\
\hline ECOG performance status & 35 & 17.5 \\
- 0 & 111 & 55.5 \\
- 1 & 44 & 22.0 \\
- 2 & 8 & 1.0 \\
- 3 & & \\
- not evaluable & & \\
\hline
\end{tabular}

At the time of the interview $48 \%$ received intravenous and $17 \%$ oral chemotherapy. $70 \%$ were married or lived in a steady relationship, $14 \%$ were widowed and $16 \%$ were divorced or lived without a partner. $52 \%$ named one, 
$38 \%$ multiple and $11 \%$ no caregiver. The mean number of caregivers of all patients was $1.3(0-4)$, no statistically significant difference could be found between women (1.3) and men (1.2). For $61 \%$ the partner was a caregiver, $38 \%$ named children, $10 \%$ siblings and $7 \%$ friends.

\subsubsection{Distress Outcomes (DT)}

Mean distress level was 4.7 with $35 \%$ scoring above cut-off $>5$ and $55 \%$ scoring above cut-off $\geq 5$ thus fulfilling criteria for intervention (Mehnert et al., 2006). Women (4.8) showed a higher distress level compared to men (4.3) $(\mathrm{p}=0.038)$. Statistically not significant was the mean difference between the 3 age groups up to 60 years $(4.9), 61$ to 70 years (4.7) and 71 years and older (4.4). According to ECOG performance status it could be observed that patients are more distressed the worse their general condition is $(0=3.4,1=4.6,2=5.4)(p=0.005)$. Further variance analyses showed no significant association between level of distress and type of therapy or tumor site. The mean distress level and proportion of persons scoring above cut-off $>5$ is depicted in table 2 .

Table 2. Results of the DT - Mean distress level with standard deviations (SD) and proportions of patients and caregivers scoring above cut-off $(>5)$

\begin{tabular}{|c|c|c|}
\hline & Mean (SD) & $\%$ above cut-off $(>5)$ \\
\hline \multicolumn{3}{|l|}{ PATIENTS } \\
\hline Total $(\mathrm{N}=193)$ & $4.7(2.7)$ & 34.7 \\
\hline \multicolumn{3}{|l|}{ Gender } \\
\hline - $\operatorname{men}(n=67)$ & $4.3(2.6)$ & 32.8 \\
\hline - women $(n=126)$ & $4.8(2.7)$ & 35.7 \\
\hline \multicolumn{3}{|l|}{ Age at the time of the interview } \\
\hline - up to 60 years $(n=63)$ & $4.9(2.7)$ & 39.7 \\
\hline - $61-70$ years $(n=56)$ & $4.7(2.5)$ & 33.9 \\
\hline - older than 70 years $(n=74)$ & $4.4(2.7)$ & 31.1 \\
\hline \multicolumn{3}{|l|}{ Diagnoses } \\
\hline - breast cancer $(n=81)$ & $4.6(2.7)$ & 34.6 \\
\hline - other tumors $(\mathrm{n}=112)$ & $4.7(2.7)$ & 34.8 \\
\hline \multicolumn{3}{|l|}{ ECOG performance status } \\
\hline$-0(n=34)$ & $3.4(2.6)$ & 20.6 \\
\hline$-1(n=107)$ & $4.6(2.6)$ & 35.5 \\
\hline$-2(n=42)$ & $5.4(2.6)$ & 38.1 \\
\hline \multicolumn{3}{|l|}{ CAREGIVERS } \\
\hline Total $(\mathrm{N}=132)$ & $5.4(2.8)$ & 47.7 \\
\hline \multicolumn{3}{|l|}{ Gender } \\
\hline$-\operatorname{men}(\mathrm{n}=55)$ & $5.4(2.5)$ & 47.3 \\
\hline - women $(n=77)$ & $5.4(2.9)$ & 48.1 \\
\hline \multicolumn{3}{|l|}{ Age at the time of the interview } \\
\hline - up to 60 years $(n=56)$ & $5.6(2.7)$ & 51.8 \\
\hline - older than 60 years $(n=60)$ & $4.9(2.7)$ & 38.3 \\
\hline \multicolumn{3}{|l|}{ Living in the same household } \\
\hline - yes $(\mathrm{n}=88)$ & $5.6(2.7)$ & 51.1 \\
\hline- no $(n=44)$ & $5.0(2.9)$ & 40.9 \\
\hline \multicolumn{3}{|l|}{ Own physical or mental problems } \\
\hline- yes $(n=77)$ & $5.8(2.6)$ & 55.8 \\
\hline- no $(n=55)$ & $4.9(2.9)$ & 36.4 \\
\hline
\end{tabular}


Problems most frequently described in the PL were fatigue (61\%), getting around (49\%), pain (44\%), fears $(43 \%)$, worry ( $42 \%)$ and sleep $(42 \%)$.

\subsection{Results of the Caregiver-Interviews}

137 patients' caregivers were interviewed. The median age was $61.5(25-86), 42 \%$ were male, $58 \%$ female. In $91 \%$ one caregiver per patient was questioned, in $9 \%$ two or three. The interviewed caregiver was the patients' partner in $66 \%$ and a patients' child in $23 \%$. Further respondents were mother (4\%), sibling (3\%), friend (3\%) and sister in law (1\%). Only $13 \%$ of the caregivers were not living in the same location as the patient, $66 \%$ lived in the same household. $58 \%$ mentioned having physical or mental problems themselves, including heart disease $(16 \%)$, spinal disc problems $(7 \%)$ or diabetes $(6 \%)$. Caregivers themselves received support in most cases by partner $(41 \%)$, of which it was in $20 \%$ the cancer patient. Further important sources of support were: children (31\%), friends (26\%) and siblings (14\%). Professional supporters such as psychotherapist (4\%) or general practitioner $(2 \%)$ were named only seldom. $15 \%$ of the caregivers did not receive any support.

\subsubsection{Distress Outcomes (DT)}

Mean distress level was 5.4 , with $48 \%$ scoring above cut-off $>5$ and $67 \%$ scoring above cut-off $\geq 5$. Female and male caregivers showed an identical score of 5.4, further subgroup comparisons are depicted in table 2. Pearson's correlation between patients' and caregivers' distress was weak $(\mathrm{r}=0.19)$, but statistically significant at the $5 \%$ level $(\mathrm{p}=0.028)$. This association was higher when both lived in the same household $(\mathrm{r}=0.24, \mathrm{p}=0.027)$.

Overall caregivers achieved a considerable higher level of distress (5.4) than female (4.8) and especially male patients (4.3). In a two-way analysis of variance (ANOVA) the factors "gender" and "role" with the factor levels "male" vs. "female" and "patient" vs. "caregiver" were evaluated. Statistical significance reached only the factor "role" ( $\mathrm{p}=0.008)$, "gender" was, as well as the interaction between "gender" and "role", not significant.

The applied test of normal distribution was highly significant $(\mathrm{p}<0.001)$ which means that with high probability distress is not normally distributed in the sample.

\subsubsection{Anxiety and Depression Outcomes (HADS-D)}

Mean result on the anxiety subscale was 7.2 , with $20 \%$ scoring above cut-off ( $\geq 11)$ which means that they could be regarded as anxious in a clinical sense. The assessment of depression showed a mean score of 4.9 , with $15 \%$ scoring above cut-off $(\geq 9)$. Results of the subgroups are depicted in table 3 .

Table 3. Results of the HADS-D: Means with standard deviations (SD) and proportions of caregivers scoring above cut-offs (Anxiety $\geq 11$; Depression $\geq 9$ )

\begin{tabular}{lcccc}
\hline & \multicolumn{2}{c}{ Anxiety } & \multicolumn{2}{c}{ Depression } \\
& $\begin{array}{c}\text { Mean } \\
\text { (SD) }\end{array}$ & $\begin{array}{c}\text { \% above } \\
\text { cut-off }(\geq 11)\end{array}$ & $\begin{array}{c}\text { Mean } \\
\text { (SD) }\end{array}$ & $\begin{array}{c}\text { \%bove } \\
\text { cut-off }(\geq 9)\end{array}$ \\
\hline TOTAL $(\mathrm{N}=136 / \mathrm{N}=137)$ & $7.2(4.1)$ & 19.9 & $4.9(3.8)$ & 14.6 \\
Men ( $=57)$ & $7.4(3.9)$ & 22.8 & $5.0(3.5)$ & 14.0 \\
Women (n=79/n=80) & $7.1(4.3)$ & 17.7 & $4.8(4.0)$ & 15.0 \\
up to 60 years $(\mathrm{n}=58)$ & $7.6(4.3)$ & 24.1 & $5.1(4.1)$ & 15.5 \\
older than 60 years $(\mathrm{n}=61 / \mathrm{n}=62)$ & $6.3(3.3)$ & 11.5 & $4.5(3.2)$ & 9.7 \\
lives in the same household (n=90/n=91) & $7.6(4.1)$ & 23.3 & $5.6(3.9)$ & 17.6 \\
does not live in the same household $(\mathrm{n}=46)$ & $6.3(3.9)$ & 13.0 & $3.6(3.4)$ & 8.7 \\
own problems $(\mathrm{n}=78 / \mathrm{n}=79)$ & $7.7(4.3)$ & 20.5 & $5.7(4.1)$ & 20.3 \\
no own problems $(\mathrm{n}=58)$ & $6.4(3.7)$ & 19.0 & $3.9(3.1)$ & 6.9 \\
\hline
\end{tabular}

The conducted reliability analysis showed a Cronbach's $\alpha$ of .88 (total score), Pearson's correlation coefficient between the subscales was $\mathrm{r}=0.76(\mathrm{p}<0.001)$. The total HADS-D score, as a measurement of global distress, was 12.1 in mean with $24 \%$ scoring above cut-off in almost one of the two subscales. Pearson's correlation between total HADS-D and DT was $\mathrm{r}=0.59(\mathrm{p}<0.001)$. 


\section{Discussion}

In the present analysis the number of caregivers or their relationship to the patient was not restricted. Nevertheless, it becomes clear that the vast majority of patients has only a limited number of caregivers, and these are particularly partners and children. This conclusion would not have been possible if we had concentrated only on partners or children in advance. We furthermore included different entities of solid tumors but we built a homogenous group because of the metastatic stage of disease. When selecting the screening questionnaires we paid attention to the fact that it was an established and proven tool in everyday practice.

\subsection{Distress Outcomes: Extent of Patients' and Caregivers' Distress}

Our study reveals a mean distress level of 4.7 for patients with $35 \%$ scoring above cut-off $>5$. This result fits well to findings in an outpatient setting with comparable populations (Mergenthaler et al., 2011; Weide et al., 2012) and therefore seems to be quite robust. Furthermore $35 \%$ of cancer patients with varying sites and stages were found to be distressed in another study where the Brief Symptom Inventory was used as screening instrument (Zabora, BrintzenhofeSzoc, Curbow, Hooker, \& Piantadosi, 2001). In sum approximately one third of patients with a metastatic solid tumor who are treated in an outpatient setting could be regarded as distressed. But there are hints from various studies that this figure is quite comparable to matched control groups and general population (Hagedoorn et al., 2008). These findings depend obviously on the chosen cut-off value but we believe that a cut-off should not be too low because of lacking discrimination abilities. The subjectively experienced distress should furthermore not be attributed to cancer in whole. Of course it might be a stressor and it is necessary to screen patients and to offer help but one should focus on the subgroup of highly distressed persons instead of regarding every patient per se as distressed because of a cancer diagnosis.

The proportion of distressed caregivers however was almost 50\% (48\% scoring above cut-off $>5$ ) and was therefore higher than among the severely ill patients. This result is consistent with findings from some other studies (Janda et al., 2008; Hasson-Ohayon, Goldzweig, Braun, \& Galinsky, 2010; Nordin, Wasteson, Hoffman, Glimelius, \& Sjödén, 2001). It may be explained in the way that the caregiver lacks control and has to watch how the patient suffers who has in contrast more of a sense of control (Hagedoorn et al., 2008). Another explanation might be the neglected support needs of the caregivers who are perceived as caregivers and not as potential care recipients (Hasson-Ohayon et al., 2010). The phenomenon that caregivers who live with the care recipient experience a higher level of distress (Schulz \& Beach, 1999) could be replicated by our results as well.

After all it is important to note that not all caregivers classified as "distressed" qualify for a clinical diagnosis. Furthermore it could be shown that there is only a weak association between caregivers' distress and desire for formal psychological support (Merckaert et al., 2013).

\subsection{Distress Outcomes: Association between Patients' and Caregivers' Distress and Impact of Gender and Role}

Caregivers seem to be more distressed than patients themselves but what about the association between patients' and caregivers' distress? In a meta-analysis of 21 studies the overall effect size of correlation between patient and caregiver distress was $\mathrm{r}=0.35$ (Hodges et al., 2005), a further meta-analysis found an association of $\mathrm{r}=0.29$ (Hagedoorn et al., 2008). So there is strong evidence for an association between patients' and caregivers' distress but the correlation is only moderate. In our study we also found a weak correlation $(\mathrm{r}=0.19)$ although it reached statistical significance at the $5 \%$ level.

A recent meta-analysis by Hagedoorn et al. (2008) pointed out that in many studies the patient-partner role is confounded by gender and it underlined the idea that women are in general more distressed than men, regardless of role (patient vs. caregiver): "There was no empirical support for the notion of persons with cancer being more distressed than the partners, or vice versa, once gender was taken into account." (Hagedoorn et al., 2008; p. 18). Our results do not support this finding because the conducted ANOVA showed no gender influence. However one has to take into account that the DT is not normally distributed but the ANOVA seems to be robust to these limitations. Against this background, one could critically consider the DT - although it is well established because of its lacking psychometric properties.

\subsection{Main Issues of Caregivers'Psychosocial Distress}

The HADS-D appeared highly reliable $(\alpha=.88)$ in our analysis and the correlation between the subscales $(\mathrm{r}=0.76)$ was at the expected .70 level (Bjelland et al., 2002). This strong correlation is explained by a common causal factor (Bjelland et al., 2002), which could be regarded as "global distress". In our survey we validated this concept with the help of the DT and found a moderate correlation of $\mathrm{r}=.59(\mathrm{p}<0.001)$. It is important to note that this finding does not contradict the postulated HADS-D structure, because there is convincing evidence for the validity of two factors (Gough \& Hudson, 2009). Further results in outpatient settings underline a moderate to 
high association between HADS-D and DT which means that both instruments seem to measure a similar construct (Zwahlen et al., 2008).

In the present analysis the mean anxiety-score was 7.2 and the mean depression-score amounted to 4.9 , with $20 \%$ and $15 \%$ scoring above cut-off-values $(\geq 11 / 9)$. In other studies the proportion of above cut-off scores $(\geq$ 11) varied between $7 \%-40 \%$ for anxiety and 5\% - 12\% for depression (Price et al., 2010; Gough \& Hudson, 2009; Janda et al., 2008; Friðriksdóttir et al., 2011). A quite comparable study found $16 \%$ of caregivers to be anxious (cut-off $\geq 11$ ) and $11 \%$ to be depressed (cut-off $\geq 9$ ) (Zwahlen et al., 2008). But although the same cut-offs were used in the same setting different results have to be interpreted with caution with respect to varying stages of disease. In summary the dimensions of anxiety and depression vary widely between studies, depending on many different variables such as cancer site, stage, caregiver's gender, clinical setting, etc. It would be helpful to analyze the different values in a meta-analysis to get an idea of the dimensions and issues of distress among caregivers. A review concludes that only a minority of caregivers develops psychiatric disorders but a greater number develops high levels of emotional distress (Pitceathly \& Maguire, 2003).

Our data provides further evidence for an important proportion of (clinically) significant anxiety and depression among caregivers of patients with a metastatic solid tumor. But one should keep in mind that according to a current overview of mental disorders in Europe the 12-month prevalence of anxiety disorders is estimated to be $14 \%$ and $7 \%$ for major depression (Wittchen et al., 2011). In this regard we can state that caregivers in our survey showed a moderate elevation in anxiety and depression, and if one understands this finding in a broader sense as global distress, showed a moderate elevation in distress. These findings fit well to the results of a meta-analysis by Hagedoorn et al. (2008).

\subsection{Methodological Aspects}

Unlike many other studies on psychosocial distress the relationship of patient and caregiver was not predetermined in the present study. It depended only on the patient which person was named as caregiver and therefore had the chance to be interviewed. The response rate of $53 \%$ seems to be acceptable, but it could be improved.

Although we had a homogenous sample of patients, because of metastatic disease, gender and role ("patient" vs. "caregiver") varied. So it was possible for us to analyze distress of patients and caregivers with respect to the effects of gender and role. But to investigate this gender-effect it would have been helpful if the patients had answered the HADS-D as well because of its psychometric properties. We decided to use the DT as a screening tool because it is a standardized, well-established and easy to use instrument which is very helpful in routine care but it failed to reach normal distribution and its psychometric properties are limited.

Although HADS-D cut-off-values are well published it remains unclear what anxiety or depression in a "clinical sense" means. One has to keep in mind that a standardized instrument cannot replace a clinical interview or a psychiatric diagnosis. And by design, the number of caregivers classified as high risk based on a screening instrument has to be greater than the number of caregivers who qualify for a clinical diagnosis (Vanderwerker et al., 2005). It does not make sense to pathologize a great number of caregivers who show to some extent a normal and healthy reaction towards a life-threatening situation. With respect to global distress one has to consider that according to the HADS-D total score $24 \%$ and according to the DT $48 \%$ were significantly distressed. Maybe it would be helpful to approach the instruments stepwise which means to screen at first with the help of the DT and to validate the screening-result on a more discriminate level by the HADS-D.

The outpatient setting in which the interviews took place is important to note because there is only little data available. In general a survey of patients with metastatic disease and their caregivers is a complex challenge (Grov, Fosså, Tønnessen, \& Dahl, 2006). In our study we were able to carry out the interviews in close proximity to the place of treatment which may have biased the results. But we had to consider the severe illness of the patient cohort and we still believe that it was the best way from a practical standpoint to conduct the interviews.

The metastatic stage of disease is perhaps the most striking strength of the project. As pointed out in a review many studies investigate patients (and caregivers) in an early stage and one can imagine that distress could be completely different in the palliative situation (Hagedoorn et al., 2008).

Limitations to the present study were the lack of a comparison group and the cross-sectional approach. We assessed psychosocial distress only at a single time point and do not know how it would develop in the course of the disease. 


\section{Conclusion}

Caregivers of outpatient cancer patients in a metastatic stage of disease are highly distressed, sometimes even more than the patients themselves. An important proportion of these caregivers have been screened as anxious and depressed in a clinical sense. There is a weak association between patients' and caregivers' distress but the patients' distress is no predictor of the caregivers' distress. No effect of gender on the distress level could be observed.

In conclusion all caregivers should be screened to identify persons at risk and they should be offered an individual intervention to prevent physical or psychological health problems. In this context it is important to clarify which healthcare professional is responsible for caregivers: oncologist, general practitioner, psychotherapists? Currently caregivers have to become patients themselves to receive help from the healthcare system - it would be better to offer preventive measures to an identified small high-risk group of caregivers.

\section{References}

Berufsverband der Niedergelassenen Hämatologen und Onkologen in Deutschland - BNHO e.V. (2013). Die KrebsSpezialisten. Weil Kompetenz und Engagement zählen. http://www.bnho.de/fileadmin/user_upload/dateien/Dokumente_ab_12.10/BNHO_Flyer_L_DIN_web_5-10 .pdf. Accessed 08 January 2013

Bjelland, I., Dahl, A. A., Haug, T. T., \& Neckelmann, D. (2002). The validity of the hospital anxiety and depression scale. An updated literature review. $J$ Psychosom Res, 52, 69-77. http://dx.doi.org/10.1016/S0022-3999(01)00296-3

Braun, M., Mikulincer, M., Rydall, A., Walsh, A., \& Rodin, G. (2007). Hidden Morbidity in Cancer: Spouse Caregivers. J Clin Oncol, 25(30), 4829-4834. http://dx.doi.org/10.1200/JCO.2006.10.0909

Friðriksdóttir, N., Saevarsdóttir, T., Halfdánardóttir, S. Í., Jónsdóttir, A., Magnúsdóttir, H., Olafsdóttir, K. L., ...Gunnarsdóttir, S. (2011). Family members of cancer patients: Needs, quality of life and symptoms of anxiety and depression. Acta Oncol, 50(2), 252-258. http://dx.doi.org/10.3109/0284186X.2010.529821

Götze, H., Weißflog, G., Brähler, E., Romer, G., Bergelt, C., von Klitzing, K., ... Ernst, J. (2012). Partner von Krebspatientinnen mit minderjährigen Kindern - Psychische Belastung im Vergleich zur Allgemeinbevölkerung und zur krebskranken Partnerin. Psychother Psych Med, 62, 73-79. http://dx.doi.org/10.1055/s-0032-1301899

Gough, K., \& Hudson, P. (2009). Psychometric properties of the Hospital Anxiety and Depression Scale in family caregivers of palliative care patients. $J$ Pain Symptom Manage, 37(5), 797-806. http://dx.doi.org/10.1016/j.jpainsymman.2008.04.012

Grov, E. K., Dahl, A. A., Moum, T., \& Fosså, S. D. (2005). Anxiety, depression, and quality of life in caregivers of patients with cancer in late palliative phase. Ann Oncol, 16, 1185-1191. http://dx.doi.org/10.1093/annonc/mdi210

Grov, E. K., Fosså, S. D., Tønnessen, A., \& Dahl, A. A. (2006). The caregiver reaction assessment: psychometrics, and temporal stability in primary caregivers of Norwegian cancer patients in late palliative phase. Psycho-Oncology, 15(6), 517-527. http://dx.doi.org/10.1002/pon.987

Hagedoorn, M., Sanderman, R., Bolks, H. N., Tuinstra, J., \& Coyne, J. C. (2008). Distress in couples coping with cancer: a meta-analysis and critical review of role and gender effects. Psychol Bull, 134(1), 1-30. http://dx.doi.org/10.1037/0033-2909.134.1.1

Hasson-Ohayon, I., Goldzweig, G., Braun, M., \& Galinsky, D. (2010). Women with advanced breast cancer and their spouses: diversity of support and psychological distress. Psycho-Oncology, 19(11), 1195-1204. http://dx.doi.org/10.1002/pon.1678

Herrmann-Lingen, C., Buss, U., \& Snaith, R. P. (2005). HADS-D: Hospital Anxiety and Depression Scale Deutsche Version. Verlag Hans Huber, Bern.

Heußner, P., Besseler, M., Dietzfelbinger, H., Fegg, M., Lang, K., Mehl, U., ... Sellschopp, A. (eds.) (2009). Manual Psychoonkologie - Empfehlungen zur Diagnostik, Therapie und Nachsorge. W. Zuckschwerdt Verlag, München.

Hodges, L. J., Humphris, G. M., \& Macfarlane, G. (2005). A meta-analytic investigation of the relationship between the psychological distress of cancer patients and their carers. Soc Sci Med, 60(1), 1-12. http://dx.doi.org/10.1016/j.socscimed.2004.04.018 
Janda, M., Steginga, S., Dunn, J., Langbecker, D., Walker, D., \& Eakin, E. (2008). Unmet supportive care needs and interest in services among patients with a brain tumour and their carers. Patient Educ Couns, 71(2), 251-258. http://dx.doi.org/10.1016/j.pec.2008.01.020

Mehnert, A., Müller, D., Lehmann, C., \& Koch, U. (2006). Die deutsche Version des NCCN Distress-Thermometers - Empirische Prüfung eines Screening-Instruments zur Erfassung psychosozialer Belastung bei Krebspatienten. Zeitschrift für Psychiatrie, Psychologie und Psychotherapie, 54(3), 213-223. http://dx.doi.org/10.1024/1661-4747.54.3.213

Merckaert, I., Libert, Y., Lieutenant, F., Mocheux, A., Farvacques, C., Slachmuylder, J.-L., \& Razavi, D. (2013). Desire for formal psychological support among caregivers of patients with cancer: prevalence and implications for screening their needs. Psycho-Oncology, 22(6), 1389-95. http://dx.doi.org/10.1002/pon.3153

Mergenthaler, U., Heymanns, J., Köppler, H., Thomalla, J., van Roye, C., Schenk, J., \& Weide, R. (2011). Evaluation of psychosocial distress in patients treated in a community-based oncology group practice in Germany. Ann Oncol, 22(4), 931-938. http://dx.doi.org/10.1093/annonc/mdq455

Mitchell, A. J. (2007). Pooled results from 38 analyses of the accuracy of distress thermometer and other ultra-short methods of detecting cancer-related mood disorders. J Clin Oncol, 25(29), 4670-4681. http://dx.doi.org/10.1200/JCO.2006.10.0438

Nordin, K., Wasteson, E., Hoffman, K., Glimelius, B., \& Sjödén, P. O. (2001). Discrepancies between attainment and importance of life values and anxiety and depression in gastrointestinal cancer patients and their spouses. Psycho-Oncology, 10(6), 479-489. http://dx.doi.org/10.1002/pon.536

Northouse, L., Williams, A.-L., Given, B., \& McCorkle, R. (2012). Psychosocial Care for Family Caregivers of Patients with Cancer. J Clin Oncol, 30(11), 1227-1234. http://dx.doi.org/10.1200/JCO.2011.39.5798

Pitceathly, C., \& Maguire, P. (2003). The psychological impact of cancer on patients' partners and other key relatives: a review. Eur J Cancer, 39, 1517-1524. http://dx.doi.org/10.1016/S0959-8049(03)00309-5

Price, M. A., Butow, P. N., Costa, D. S., King, M. T., Aldridge, L. J., Fardell, J. E., ... Webb, P. M.; Australian Ovarian Cancer Study Group; Australian Ovarian Cancer Study Group Quality of Life Study Investigators (2010). Prevalence and predictors of anxiety and depression in women with invasive ovarian cancer and their caregivers. Med J Aust, $193(5 \mathrm{Suppl})$, S52-57.

Schulz, R., \& Beach, S. R. (1999). Caregiving as a risk for mortality: the Caregiving Health Effects Study. JAMA, 282, 2215-2219. http://dx.doi.org/10.1001/jama.282.23.2215

Stenberg, U., Ruland, C. M., \& Miaskowski, C. (2010). Review of the literature on the effects of caring for a patient with cancer. Psycho-Oncology, 19(10), 1013-1025. http://dx.doi.org/10.1002/pon.1670

Vanderwerker, L. C., Laff, R. E., Kadan-Lottick, N. S., McColl, S., \& Prigerson, H. G. (2005). Psychiatric Disorders and Mental Health Service Use Among Caregivers of Advanced Cancer Patients. J Clin Oncol, 23(28), 6899-6907. http://dx.doi.org/10.1200/JCO.2005.01.370

Weide, R., Feiten, S., Friesenhahn, V., Heymanns, J., Kleboth, K., Mergenthaler, U., ... Köppler, H. (2012). Identifying Caregivers and Their Meaning for Patients with Metastatic Solid Tumours in Routine Care: A Survey at a Community-Based Oncology Group Practice in Germany. Cancer and Clinical Oncology, 1(1), 41-51. http://dx.doi.org/cco.v1n1p41

Williams, A. L., \& McCorkle, R. (2011). Cancer family caregivers during the palliative, hospice, and bereavement phases: a review of the descriptive psychosocial literature. Palliat Support Care, 9(3), 315-325. http://dx.doi.org/10.1017/S1478951511000265

Wittchen, H. U., Jacobi, F., Rehm, J., Gustavsson, A., Svensson, M., Jönsson, B., ... Steinhausen, H. C. (2011). The size and burden of mental disorders and other disorders of the brain in Europe 2010. Eur Neuropsychopharmacol, 21(9), 655-679. http://dx.doi.org/10.1016/j.euroneuro.2011.07.018

Zabora, J., BrintzenhofeSzoc, K., Curbow, B., Hooker, C., \& Piantadosi, S. (2001). The prevalence of $\begin{array}{lllll}\text { psychological distress by cancer site. Psycho-Oncology, } & 10, & 19-28 .\end{array}$ http://dx.doi.org/10.1002/1099-1611(200101/02)10:1<19::AID-PON501>3.0.CO;2-6

Zwahlen, D., Hagenbuch, N., Carley, M. I., Recklitis, C. J., \& Buchi, S. (2008). Screening cancer patients' families with the distress thermometer (DT): a validation study. Psycho-Oncology, 17, 959-966. http://dx.doi.org/10.1002/pon.1320 


\section{Copyrights}

Copyright for this article is retained by the author(s), with first publication rights granted to the journal.

This is an open-access article distributed under the terms and conditions of the Creative Commons Attribution license (http://creativecommons.org/licenses/by/3.0/). 